
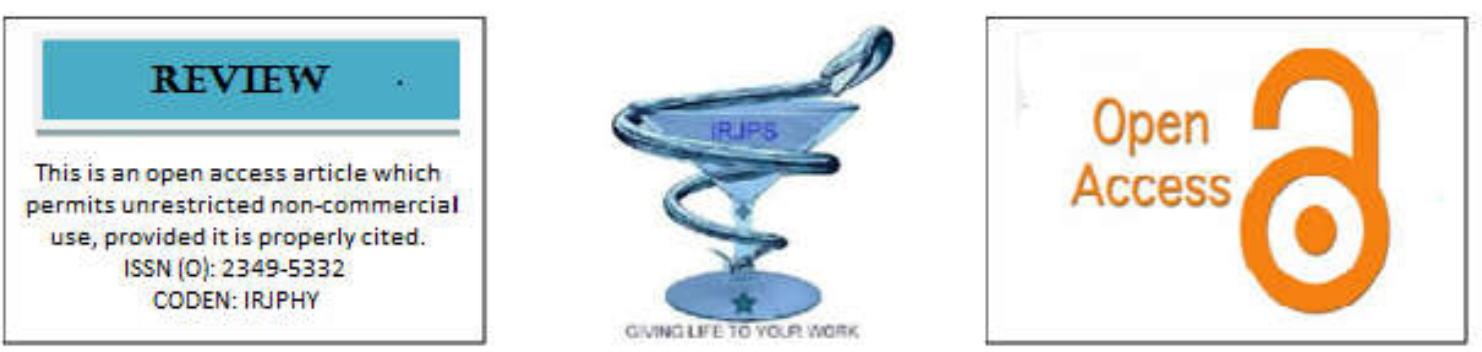

\title{
DRUG DISCOVERY AND DEVELOPMENT: AN OVERVIEW
}

\section{Bhavik Sharma}

Madhav University, Rajasthan, India

\begin{abstract}
The processes by which drugs are discovered and designed are known as drug discovery. It is a process whichaim at identifying a compound therapeutically useful in curing \& treating disease.It involves the identification of candidates, synthesis, characterization, screening \& assays for therapeutic efficacy.human body made up of many chemical machineries like protein, carbohydrates, minerals etc. human body has also been provided with all the necessary chemical components or precursors, various enzymes and neurotransmitters for the balanced and proper functioning of all the life sustaining processes.Developing a new drug from original idea to the launch of a finished product is a complex process it can take many years of research and take lots of money."Pharmacognosy" the term used to investigation of medicinal substances. In which plants, animals, or minerals are in their crude or unprepared state. Cheminformatics or Chemo informatics is another method to reach the destiny of drug discovery. Drug design and development is a challenging, expensive, and time consuming, although this process has beenaccelerated due to the development of computational tools and methodologies.Present days,computational methods and structure-based drug design informatic technologies are used and speeded up the drug discoveryprocess in an efficient manner.
\end{abstract}

KEYWORD- Drug discovery, cheminformatics, Rational drug design, Computational approx.

\author{
Corresponding Authors: Bhavik Sharma \\ E-mail: bhawik2011sharma@gmail.com
}

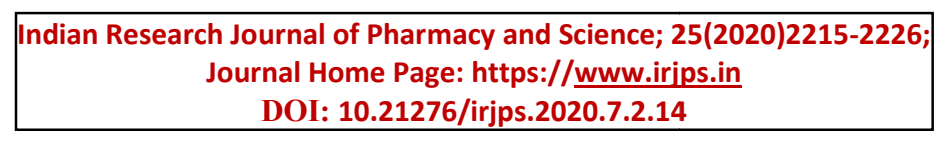




\section{INTRODUCTION}

Drug discovery is a process, which aims at identifying a compound therapeutically useful in treating and curing a disease. drug discovery shows a biological target that has play a role in the development of the disease or starts from a molecule with interesting biological activities. ${ }^{1,2}$ Some process is involving in drug discovery are identification of candidates, synthesis, characterization, screening, and assays for therapeutic efficacy. Research has been occurring in academia in which data has been generated to develop a hypothesis that the inhibition or activation of a protein or pathway will result in a therapeutic effect in a disease state. ${ }^{3,4}$ As the drug discovery process has evolved, it has been focusing on macromolecular targets. tools which were used in drug discovery are X-ray crystallography, molecular modeling, PCR, and recombinant DNA technologies provided a sharper and sharper picture of the biological targets impacted by drugs. ${ }^{5}$

Modern Drug Discovery: -There are certain steps for drug discovery

\section{Step 1: Target identification}

Identification of target is the first stage in drug discovery. a target is the specific binding site of the drug through which the drug showstheir action. ${ }^{6}$ Some characteristics are: -

1. The drug target is a biomolecule, normally a protein that couldexist in isolated or complex modality.

2. The biomolecules have special sites.

3. The biomolecular structure change when the biomolecule is bind to small molecules and the structure are changed normally or reversible.

4. when the biomolecule structure is changed a Physiological response occurs and it induced regulation of cell, tissues or body status.

5. the change in biomolecular structure play a major role in complex regulation and have a pathological condition.
6. In pathological process, the expression, activity and structure of the biomolecule might get changed.

7. the small molecules binding to the biomolecular are drugs.

For a diseases condition or a specific disease, a drug target is the key molecules. but the drug target itself has some limitations and debated with the pharmaceutical industries.7,8,9

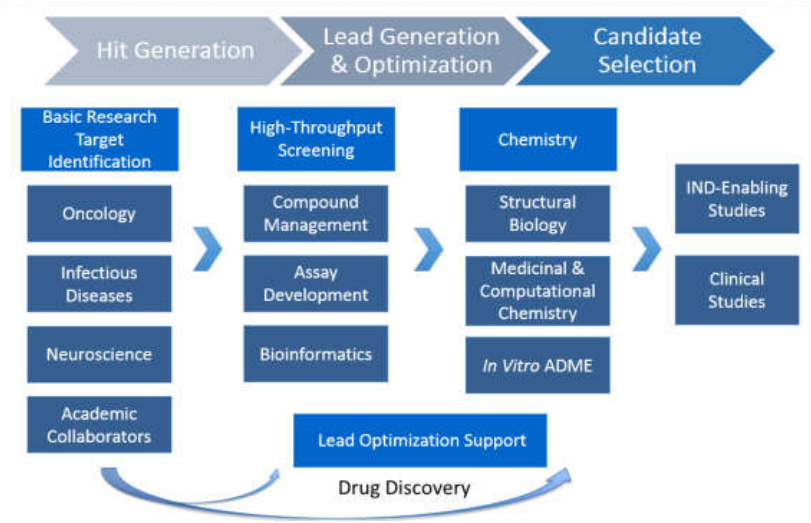

Fig 1: Steps in drug discovery

\section{STEP 2: Target validation}

Drug discovery is thought of discovery, creation and design of a compound that possess the potential to become useful therapeutic. ${ }^{10}$ It is very expensive, time consuming, and difficult process that involves the identification of candidates and synthesis,characterization, screening, and assays of their therapeutic efficacy. Physiologically, Pathologically, and Pharmacologically are the process in validating the new drug targets. It evaluating a biomolecule and might be performed at the molecular, cellular, or whole animal level. ${ }^{11,12}$

\section{What are drug targets?}

Target identification and validation are the first key stages in the drug discoverya drug targetis the specific binding site of a drug in vivo throughwhich the drug exerts its action. ${ }^{13}$ Drug targetmight have the following characteristics:

1) Thedrug target is a biomolecule, normally a proteinthat could exist in isolated or complex modality. 
2)The biomolecules have special sites that match othermolecules. These molecules could be endogenous orextraneous substances such as chemical molecules(drugs). ${ }^{14,15}$

3) The biomolecular structure might changewhen the biomolecule binds to small molecules andthe changes in structure normally are reversible.

4)the change in the biomolecule's structurevarious physiological responses occur and induceregulation of the cell, organ, tissue, or body status.

5)The physiological responses triggered by the changesin biomolecule structure play a major role in complexregulation and have a therapeutic effect on pathologicalconditions. ${ }^{16,17}$

6) The expression, activity, and structure ofthe biomolecule might change over the duration of thepathological process.

7) Small molecules binding to thebiomolecules are drugs. $^{18}$

Target validation is the completely newdrug exploration and the initial step of drug discovery. It might be helpful notonly to new drug research and development but alsoprovide some details about the pathogenesis of targetrelateddiseases. ${ }^{19,20}$ There are six steps in target validation process: -

1. Discovering a biomolecule of interest.

2. Evaluating its potential as a target.

3. Designing a bioassay to measure biological activity.

4. Constructing a high-throughput screen.
5. Performing screening to find hits.

6. Evaluating the hits.

The drug discovery process starts with theidentification, or growing evidence of, biologicaltargets that are believed to be connected to a particular

condition or pathology. ${ }^{21,22}$ After the completion of biological target ofinterest, the next challenge is the conversionof the target into a bioassay that can give abiological activity. The range of potential targets islarge, from enzymes and receptors to cellular systemsthat represent an entire biochemical pathway or adisease process. After the completion of bioassay designed, high-throughput screening (HTS) method is the next key step.The basicrequirements for HTS assay are that it be sensitive, stable, highly reproducible, and robust and suitablefor screening. ${ }^{23,24,25}$ Three levels which should be performed in target validation: the molecular level, the cellular level,and the whole animal model level.HTS providedsmallchemicals which are useful tools forthe validation of new drug targets. Some HTS modelsare at the molecular level, which are cell-free systems. There is a significant differencebetween a cell and cell-free system. Atthis level, the pathological significance of the targetmight be rendered more apparent using small chemicals. The effect of the small chemicals on a cell system willprovide a tentative outline of these chemicals. $^{26,27,28}$

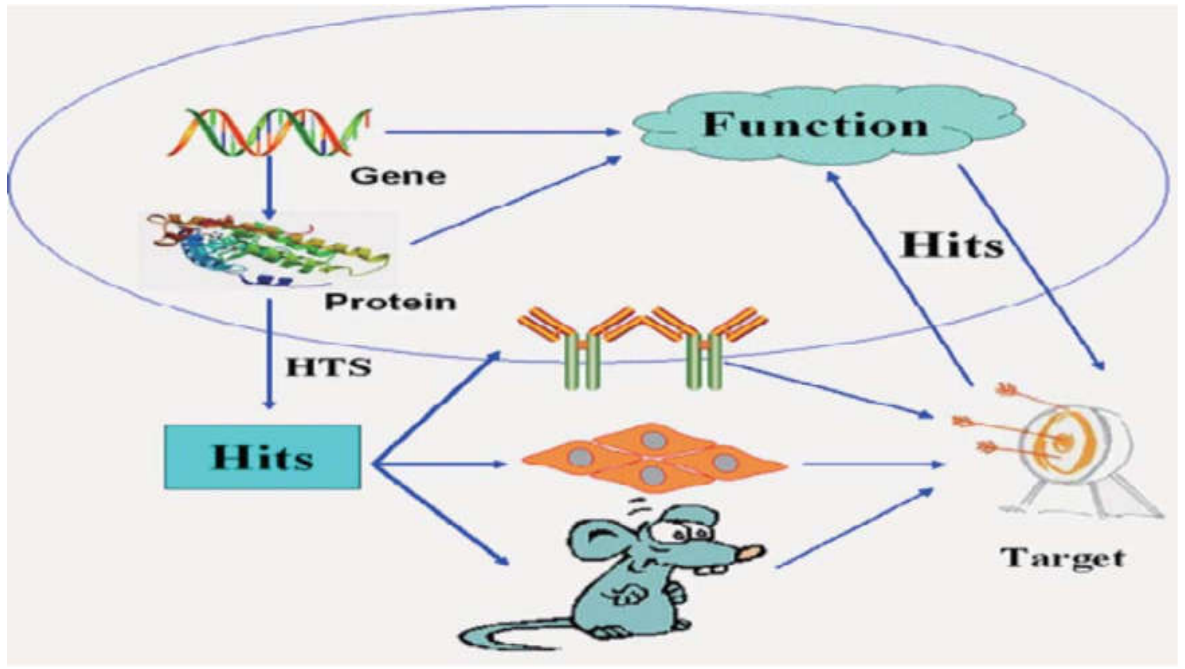

Fig 2: Drug target validation 


\section{Step 3: Lead discovery}

Once a disease- associated molecular target has been identified andvalidated in disease models, in the lead generation phase, compoundsare identified which interact with animals or disease-related cellbasedmodels. It gives information about the response of an organism to a pharmacological intervention andhelp in predicting the possible profile of new drugs ${ }^{29,30}$ This is accomplished primarily with knock-out or knock-in animalmodels; small molecule molecular target in vitro usually precedes thevalidation of the therapeutic concept in vivo; together this definesits clinical potential. ${ }^{31}$ Libraries of compounds that are either synthetic chemicals,peptides, natural or engineered proteins, or antibodies are exposedto the target in a manner that will detect and isolate those membersof the library that interact with and, preferably, have an effect on the target. The compounds selected are called "leads". Initiallyscreening can be performed by searching for compounds that bind tothe target, but binding is not sufficient for therapeutic activity. ${ }^{32,33,34}$ Morerecent screening procedures include an activity-based readout as partof the initial screening assay. For example, if the goal is to inhibit a protein that is involved in activating the expression of a particulargene or set of genes, the assay can include readout to determineif the expression of the gene is reduced by the compound. Such assays can be cell-based, but moreoften they are enzymatic assaysthat can be performed in a high-throughput manner for compounds that bind to the target, but binding is not sufficient for therapeutic activity. More recent screening procedures include an activity-basedreadout as part of the initial screening assay. ${ }^{35,36,37}$

\section{Step 4: Lead optimization}

Lead optimization is a process that begins with a compoundthat displays an interesting biological action and ends with theidentification of the best analog. Molecules are chemically modifiedand subsequently characterized in order to obtain compounds withsuitable properties to become a drug. Leads are characterized withrespect to pharmacodynamic properties such as efficacy and potencyin vitro and in vivo, Physiochemical properties, pharmacokineticproperties, and toxicological aspects. ${ }^{38,39,40}$
Step 5: Pre-clinical and clinical development

Pre-clinical development: The pre-clinical development includesthe following: develop large scale synthesis; animal safety studies;carcinogenicity tests; drug delivery; elimination and metabolismstudies; drug formulation experiments; dose-ranging studies inanimals. ${ }^{41,42,43}$

\section{Clinical development}

Clinical development has been done infive different types:

1. Treatment trail:Test for treatments or a newcombination of drugs.

2. Prevention trail: Prevent a disease or prevent itfrom returning.

3. Diagnostic trials: find better test or procedures for diagnosing adisease.

4. Screening trials: test methods of detecting diseases.

5. Quality of life trials: explore ways to improve comfort \& quality oflife for individuals with a chronic illness. ${ }^{44,45}$

Clinical trials may beclassified into 4 phases: -

Phase 0 -In phase 0 , development of promising therapeuticagents by establishing early on whether the agent behaves in humansubjects as was anticipated from preclinical studies.

Phase 1 - A small group of healthy volunteers areselected to assess the safety, tolerability, pharmacokinetics, \&pharmacodynamics of a therapy. For dose rangingstudies so that doses for clinical use can be set/adjusted.

Phase 2- Performed on larger groups \& are designedto assess the activity of the therapy, \& continue phase 1 safetyassessments.

Phase 3 - Phase 3 trial is on large patient groupsaimed at being the definitive assessment of the efficacy of the new therapy, in comparison with standard therapy.Side effects are also been monitored. It is typically expected that therebe at least two successful phase 3 clinical trials to obtain approvalfrom the FDA. Once a drug has proven acceptable, the trial results are manufacturing procedures, formulation details, shelf life, etc.

Phase 4 -In Phase 4, Post-launch safety monitoring \& ongoing technical support of a drug. Pharmaceutical company designed to detect rare or long-term adverse effects of drugs action on alarge 
patient population \& timescale than was possible during clinicaltrials. ${ }^{46,47,48,49}$

\section{Cheminformatics}

Chemoinformatic is an interface science which discovering novel chemical entities, it will result in thedevelopment of novel treatments for unmet medical needs. these methods are also applied in other fields to design new molecules. ${ }^{50}$ It consists of in-silico techniques, which are used in pharmaceuticalcompanies for drug discovery. The discovery of new medicaltreatments to meet unmet medical needs is one of the most important endeavors inhumanity. ${ }^{51,52}$ The process is time consuming, expensive, and fraught with manychallenges. now a day, the process of drug discovery has beenrevolutionized with the advent of genomics, proteomics, bioinformatics andefficient technologies like, combinatorial chemistry, cheminformatics, highthroughput screening (HTS), virtual screening, de novo design, in vitro, in silico ADMET screening, Quantitative structure-activity relationship (QSAR) and structure-based drug design.

The application of cheminformatics is it will help tostorethe information relatedto the drug molecules and the efficient presentation of such stored informationduring the process of lead optimization. $^{53,55,56}$

\section{Role of Bio and Cheminformatics in Drug} Discovery:

Two important tools(Bio and Cheminformatics), plays a major role in identifying target molecule, which could be a potential drug. ${ }^{57}$ The currentresearchers in pharmaceutical drug discovery seeks to find a particular small molecule inhibitor to bind to a specific receptor, a macromolecular target. ${ }^{58}$ These databases helpin target discovery is to infer withrelative gene expression levels. Gene expression levels are importantbecause the phenotype is determined by the small portion of genes that are expressed at any given time in a cell or tissue type, and changes in gene expressioncan be associated with disease. ${ }^{59,60}$ by comparing levels of gene expression in normal and disease states, novel drug targets can be identified by in silico methods. A drug affecting such a target is less likely to interact with a human homologue. Proteins with sequences similar across bacterial clades offer the possibility of broad-spectrum antibiotics. ${ }^{61,62}$

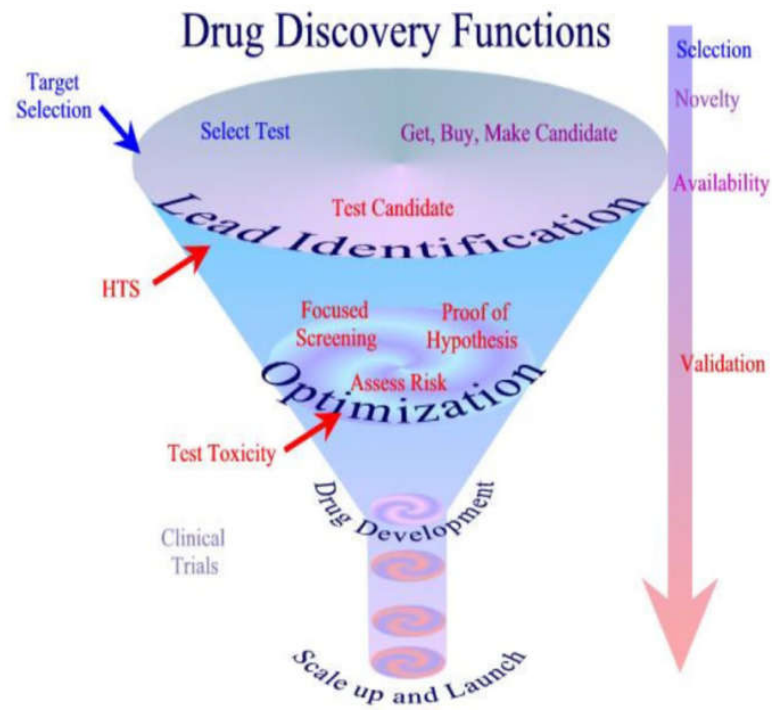

Fig 3: Milestones of Drug Discovery

\section{Evaluating a protein structure for drug design:}

After the target identifiedit is necessary to obtain accurate structural information. There are three primary methods for structure determination which are useful for drug-design: X-ray crystallography, NMR, and homology modeling. The High-resolution crystal structures are thesourcesof structural information for drug design. ${ }^{63,64}$ Proteins range in size from a few amino acids tokD. The advantage of crystallography is that water molecules are visible in the experimental data and are often useful in drug design. ${ }^{65}$ The crystal structure are used for the resolution of the diffracted amplitudes; reliability, or R factors; coordinate error; temperature factors; and chemical correctness. ${ }^{66,67}$

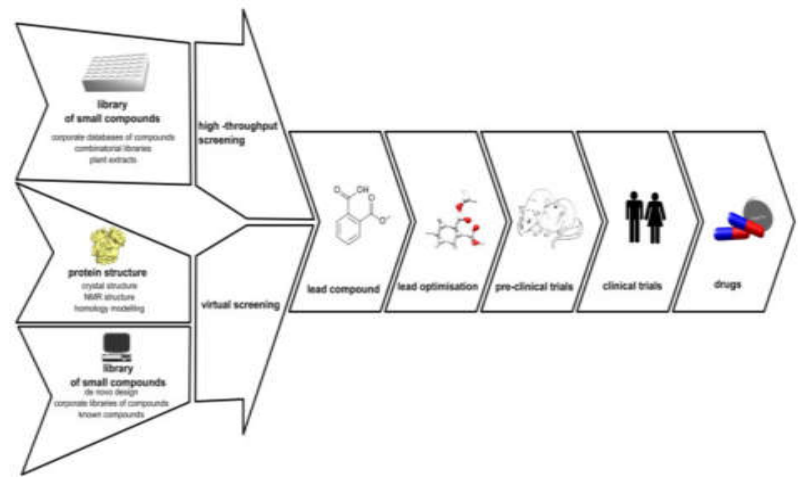

Fig 4: Steps involved in drug design

\section{COMPUTER-AIDED DRUG DESIGN}

In principle, the drug discovery process involves three

pre-clinical stages before clinical trials, namely 
target

selection, lead identification, and clinical candidate selection. ${ }^{68}$ Due to rapid advances in structural biology and computer technology, structure-based computer-aided drug design (CADD) using docking techniques, virtual screening and library design, along with target/structure focusing combinatorial chemistry, are the useful tools in the multi-step process of drug discovery. ${ }^{69}$ It is used for drug development formaking the accumulated information of existing drugs and diseases, combined with interdisciplinary inputs from other fields.As the first step in structure-based CADD, the three-dimensional (3D) structure of a target protein or nucleic acidis determined by X-ray crystallography or $\mathrm{NMR} .{ }^{70}$ Using recently constructed protein and nucleic acid databases, new computational methods use the 3D structural information of the unliganded target to design entirely newlead compounds de novo. The success application of DOCK includes the in silico virtual high throughput screen for high affinity cytochrome p450cam substrates and the computer-assisted design of selective imidazole inhibitorsfor cytochrome p450 enzymes. ${ }^{71,72}$

\section{Quantitative Structure-Activity Relationships (QSAR)}

QSAR is an example of a method which can be applied regardless of whether the structure is known or unknown, QSAR tries to formalize what is experimentally known about how a given protein interacts with some tested compounds. QSAR can be consideredas the method of trying to build a model for why some keys work and others do not. ${ }^{73,74}$

\section{Pharmacophore mapping:}

It is a set of structuralfeatures in a molecule that is recognized at a receptor site and is responsible for that molecule's biological activity. Pharmacophore Mapping is a geometrical approach. 3D model of characteristic features of the bindingsite of the protein. Pharmacophore can also be built without knowing the structure of the target. This can be done by extracting features from compounds which are known experimentally to interact with the target in question. pharmacophore model can be used to search compound databases thus screening for potential drug. ${ }^{75,76,77}$

\section{NMR-Based screening methods}

In drug discovery process NMR technology is been used. the large difference inbetween drugs and receptors and the effect that this has on therotational or translational correlation times for drugs bound to their targets. Many NMR parameters, such as the diffusion coefficient, spin diffusion, nuclear Over Hauser enhancement, and transverse and longitudinal relaxation times, are strong functions of either the overall tumbling or translation of molecules in solution. ${ }^{78,79}$ NMR techniques applicable for the elucidation of protein and nucleic acid structure. screening of drug candidates for binding to a target and the study of the conformational changes that occur in a targeton drug binding. ${ }^{80}$

\section{Factors affecting drug discovery:}

There are some important factors which affect the drug discovery anddevelopment process: -

1. Medicinal objective: In general, more precise the medicinalobjective, the less likely it is to develop a new drug; itis easy to develop an antacid but much more difficult is to developspecific proton-pump inhibitor. medicinal requirement affects the success or failure in new drug discovery. ${ }^{81}$

2. Ability of Medicinal chemist: The attributes of the chemist will influencethe outcome of evolving new drugs on the basis of molecule and biology of diseased state. $^{82}$

3. Screening facilities: A successful and rapid mass screening mainlydepends on the capacity to evaluate a large number of compounds anddetect potentially clinically useful drugs in a very short span of time. ${ }^{83}$

4. Drug development facility: chemistry, biology, pharmacy and medical groups arenecessary for drug development. $^{84}$

\section{Drug design software's}

drug development starts with the design of suitable compounds, called Ligands. These can be selected onthe basis of compounds that are recognized by the targetprotein and binds to it. ${ }^{85}$ It is a powerful tool to build alegend just based on a protein structure.The studiesare based on the shape of themoleculeinclude:

i) Fast and efficient clustering of molecules based on molecularshape.

ii) Field-based similarity computation of molecular structure. 
iii) QSARanalysis of molecules based on shape cluster. $^{86}$

\section{Rational programs used}

There are three main categories of drug design:scanners, builders, or hybrids. ${ }^{87}$

Scanners-These programs are used for screening of leadcompounds. All the database search programs fall into this category. ${ }^{88}$

\section{Strengths}

i) Complete control of user on query specifications

ii) Established synthetic feasibility of compounds tested

iii) Rapid determination of potential binding ligands iv) No scoring function required ${ }^{89,90}$

\section{Weaknesses:}

i) Requirement of a wide database of structures

ii) Diversity of potential hits is limited. There is no recombinationor derivatization of retrieved structures

Builders and Hybrids. These programs are mainly used forde novo generation of lead compounds. In these, database containsfragments or chemical building blocks instead of completecompounds and requires the attachment point of the weak binding protein. It creates a population of derivatives with improvedreceptor complementarily by recombination or derivatization fromfragments by making incremental changes iteratively. ${ }^{91,92,93}$

\section{Software used}

Software's which are used for drug design are as follows:

\section{Affinity}

- Automated, flexible docking

- the energy of the ligand/receptor complex ${ }^{94}$

2. Auto Dock (Automated Docking of FlexibleLigands to Receptors)

It consists of three separate programs: (i) Auto Dockperforms the docking of the ligand to a set ofgrids describing the target protein (ii) Auto Gridprecalculated these grids (iii) Auto Torssets up which bonds will be treated as rotatablein the ligand.

(iv) Auto Gridprecalculated these grids (v) Auto Torssets up which bonds will be treated as rotatable in the ligand ${ }^{95,96,97}$

- Provide an automated procedure for predicting the interactionof ligands with biomolecular targets and help to narrow theconformational possibilities and in identification of the mostsuitable structure $^{98}$ - A powerful approach to the problem of docking a flexiblesubstrate into the binding site of a static protein $^{99}$

- application in X-ray crystallography, SBDD, leadoptimization, virtual screening, combinatorial library design,protein-protein docking and chemical mechanism studies ${ }^{100}$

\section{Combibuild}

- Structure-based drug design program created to aid the design of combinatorial libraries.

- Screens a library possible reactant on the computer, andpredicts which ones will be the most potent - Successfully applied to find nanomolar inhibitors of

Cathepsin DDockVision ${ }^{101,102}$

\section{FRED}

- Accurate and extremely fast, multiconformer docking program

- Simple, flexible docking of ligands into binding sites on proteins

- Fast genetic algorithm for generation of configurations ${ }^{103}$

5. FlexX

- Fast computer program for predicting proteinligand interactions

- Two main applications:

(i) Complex prediction

(ii) Virtual screening (selecting a set of compounds for experimental testing)

- Conformational flexibility of the ligand; rigid protein $^{104,105}$

6.Glide

- High-throughput ligand-receptor docking for fast libraryscreening

- Fast and accurate docking program - Identifies the best binding mode through Monte Carlo sampling ${ }^{106,107}$

\section{Gold}

- Calculates docking modes of small molecules into proteinbinding sites

- Based on genetic algorithm for protein-ligand docking

- Studies full ligand and partial protein flexibility ${ }^{108,109,110}$

\section{Hint}

- Hydropathic Interactions

- Empirical molecular modeling system with new methods forde novo drug design and protein or 
nucleic acid structural analysis

- Translates the well-developed Medicinal Chemistry and QSAR formalism of $\operatorname{LogP}$ and hydrophobicity into a free energyinteraction model for all biomolecular systems based on theexperimental data from solvent partitioning ${ }^{11,112,113}$

\section{Ligplot}

- Program for automatically plotting protein-ligand interactions

- Generates schematic diagrams of protein-ligand interactionsfor a given PDB file

- Interactions shown are those mediated by hydrogen bonds and by hydrophobiccontacts ${ }^{114,115}$

\section{Situs}

- Program package for modeling of atomic resolution structuresinto low-resolution density maps - Software supports both rigid-body and flexible docking usinga variety of fitting strategies ${ }^{16,117}$ 11. Vega

- Calculates ligand-receptor interaction energy ${ }^{118}$

\section{Dock}

- Generates many possible orientations (and more recently,conformations) of a putative ligand within a user-selected regionof a receptor structure - Orientations may be scored using several schemes designed tomeasure steric and/or chemical complementarily of thereceptor-ligand complex - Evaluates likely orientations of a single ligand, or to rankmolecules from a database ${ }^{119,120,121,122}$

\section{REFERENCES}

1. Giersiefen H, Hilgenfeld R, Hillisch A (2003) Modern Methods of Drug Discovery.Institute of Molecular Biotechnology, Beutenbergster. Germany 1:

109-155.

2. Drews J (2000) Drug discovery: a historical perspective. Science 287: 1960-1963.

3. Wang S, Sim TB, Kim YS, Chang YT (2004) Tools for target identification andvalidation. CurrOpin Chem Biol 8: 371-377.

4. Du GH (2004) Evaluation and validation of drug targets. Acta Pharmacol Sin25: 1566.

5. Shayne CG (2005) Introduction: drug Discovery in the 21st Century. DrugDiscovery Handbook Wiley Press.

6. Rao VS, Das SK, Rao VJ, Gedela S (2008) Recent Developments in LifeSciences Research: Role of Bioinformatics. African Journal of Biotechnology7: 495-503.
7. Wang Y, Chiu J, He Q (2005) Proteomics in Computer-Aided Drug Design.Journal of Chemistry 1: 43-52.

8. Jens Eckstein ISOA/ARF Drug Development Tutorial. Alzheimer ResearchForum 1-18.

9. Larson RS (2006) Methods in Molecular Biology: Bioinformatics and DrugDiscovery. Department of Pathology, University of New Mexico School ofMedicine, Albuquerque, NM 1: 227-228.

10. Alderman E, Elands J (1998) A novel approach to ultra-high throughputscreening. Genet Eng. News Jan 18: 2.

11. John GH, Martyn NB, Bristol-Myers S (2002) High throughput screening forlead discovery. Burger's Medicinal Chemistry and Drug Discovery, sixth edition, Vol 2: Drug Discovery and Drug Development, Wiley Press, 37-70.

12. International Human Genome Sequencing Consortium. Finishing the EuchromaticSequence of the Human Genome. Nature 2001, 409, 861-921. 13. Pallen, M. J.; Wren, B. W. Bacterial Pathogenomics. Nature 2007, 449, 835-842.

14. Labeit, S.; Kolmerer, B. Titins: Giant Proteins in Charge of Muscle Ultrastructure andElasticity. Science 1995, 270 (5234), 293-296.

15. McDonald, N. Q.; Lapatto, R.; Rust, J. M.; Gunning, J.; Wlodawer, A.; Blundell, T. L.New Protein Fold Revealed by a 2.3-Å ResolutionCrystal Structure of Nerve GrowthFactor. Nature 1991, 354, 411-414.

16. Kumar, S.; Nussinov, R. Close-range Electrostatic Interactions in Proteins. ChemBioChem2002, 3 (7), 604-617.

17. McGaughey, G. B.; Marc Gagné, M.; Rappé, A. $\mathrm{K}$. Pi-stacking Interactions. Alive andWell in Proteins. J.Biol. Chem. 1998, 273 (25), 1545815463.

18. Ringer, A. L.; Sinnokrot, M. O.; Lively, R. P.; Sherrill, C. D. The Effect of MultipleSubstituents on Sandwich and T-shaped Pi-pi interactions." Chem. Eur. J. 2006, 12(14), 3821-3828.

19. Hunter, C. A.; Sanders, J. K. M. The Nature of pi..Pi. Interactions. J. Am. Chem. Soc.1990, 112 (14), 5525-5534.

20. a. Dougherty, D. A.; Ma, J. C. The Cation-

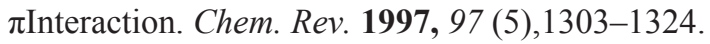

21. Burley, S. K.; Petsko, G. A. Amino-Aromatic Interactions in Proteins. FEBS Lett. 1986, 203 (2), 139-143. 
22. Lehninger, A.; Nelson, D. L.; Cox, M. M. Lehninger Principles of Biochemistry, 5th ed.; W. H. Freeman: New York, New York, 2008. 113122.

23.Kabsch, W.; Sander, C. Dictionary of Protein Secondary Structure: Pattern RecognitionofHydrogen-Bonded and Geometrical Features.Biopolymers 1983, 22 (12), 2577-2637.

24. Sumner, J. B. The Isolation and Crystallization of the Enzyme Urease: PreliminaryPaper. J. Biol. Chem. 1926, 69, 435-441.

25. Chen, L. H.; Kenyon, G. L.; Curtin, F.; Harayama, S.; Bembenek, M. E.; Hajipour, G.;Whitman, C. P. 4-Oxalocrotonate Tautomerase, an Enzyme Composed of 62 AminoAcid Residues per Monomer. J. Biol. Chem. 1992, 267 (25), 1771617721

26. Smith, S. The Animal Fatty Acid Synthase: One Gene, One Polypeptide, Seven Enzymes.FASEB J. 1994, 8 (15), 1248-1259.

27. Ridderstrom, M.; Cameron, A. D.; Jones, T. A.; Mannervik, B. Involvement of an Activesite $\mathrm{Zn}^{2+}$ Ligand in the Catalytic Mechanism of Human Glyoxalase I. J. Biol. Chem. 1998,273, 2162321628.

28. Fischer, E. Einfluss der Configuration auf die Wirkung der Enzyme. BerichteDtsch.Chem. Ges. 1894, 27 (3), 2985-2993.

29. Brown, A. Enzyme Action. J. Chem. Soc., Trans. 1902, 81, 373-388.

30. Henri, V. Theoriegenerale de l'action de quelques diastases. C. R. Acad. Sci. Paris 1902, 135, 916-919.

31. Koshland, D. E., Jr Application of a Theory of Enzyme Specificity to Protein Synthesis. Proc. Natl. Acad. Sci. 1958, 44 (2), 98-104.

32. Radzicka, A.; Wolfenden, R. A Proficient Enzyme. Science 1995, 267 (5194), 90-93.

33. Hedstrom, L. Serine Protease Mechanism and Specificity. Chem. Rev. 2002, 102 (12),4501-4524.

34. Page-McCaw, A.; Ewald, A. J.; Werb, Z. Matrix Metalloproteinases and the Regulationof Tissue Remodeling. Nat. Rev. Mol. Cell Biol. 2007, 8, 221233.

35. Aggett, P. J. Physiology and Metabolism of Essential Trace Elements: An Outline. Clin. Endocrinol. Metab. 1985, 14 (3), 513-543.

36. Gilep, A. A.; Sushko, T. A.; Usanov, S. A. At the Crossroads of Steroid HormoneBiosynthesis: the
Role, Substrate Specificity and EvolutionaryDevelopment of CYP17.Biochim. Biophys. Acta 2011, 1814 (1), 200-209.

37. Lehninger, A.; Nelson, D. L.; Cox, M. M. Lehninger Principles of Biochemistry, 5th ed.; W. H. Freeman: New York, 2008; pp 183-234.

38. Dong-Qing Wei, D. Q.; Qi-Shi Du, Q. S.; Sun, H.; Chou, K. C. Insights from Modeling the 3D Structure of H5N1 Influenza VirusNeuraminidase and its Binding Interactions with Ligands. Biochem. Biophys. Res. Commun. 2006, 344, 1048-1055.

39. Kim, C. U.; Lew, W.; Williams, M. A.; Wu, H.; Zhang, L.; Chen, X.; Escarpe, P. A.; Mendel, D. B.; Laver, W. G.; Stevens, R. C. Structure-activity Relationship Studiesof Novel Carbocyclic Influenza Neuraminidase Inhibitors. $J$. Med. Chem. 1998, 41,2451-2460.

40. Manning, G.; Whyte, D. B.; Martinez, R.; Hunter, T; Sudarsanam, S. The Protein KinaseComplement of the Human Genome. Science 2002, 298, 1912-1934.

41. Ohren, J. F.; Chen, H.; Pavlovsky, A.; Whitehead, C.; Zhang, E.; Kuffa, P.; Yan, C.;McConnell, P.; Spessard, C.; Banotai, C.; Mueller, W. T.; Delaney,A.; Omer, C.;SeboltLeopold, J.; Dudley, D. T.; Leung, I. K.; Flamme, C.; Warmus, J.; Kaufman, M.; Barrett, S.; Tecle, H.; Hasemann, C. A. Structures of Human MAP Kinase Kinase 1(MEK1) and MEK2 Describe Novel Noncompetitive Kinase Inhibition. Nat. Struct. Mol.Biol. 2004, 12, 1192-1197.

42. Fedarovich, A.; Nicholas, R. A.; Davies, C. The Role of the $\beta 5-\alpha 11$ Loop in the Active-siteDynamics of Acylated Penicillin-binding Protein a from Mycobacterium tuberculosis. J.Mol. Biol. 2012, 418, 316-330.

43. Kobilka, B. K. G Protein Coupled Receptor Structure and Activation. Biochim. Biophys.Acta 2007, 1768 (4), 794-807.

44. Langley, J. N. Observation on the Physiological Action of Extracts of the Supra-renalBodies. $J$. Physiol. 1901, 1901 (17), 231-256.

45. Dale, H. H. On Some Physiological Actions of Ergot. J. Physiol. 1906, 34, 163-206.

46. Lefkowitz, R. J.; Roth, J.; Pricer, W.; Pastan, I. ACTH Receptors in the Adrenal: Specific Binding of ACTH-125I and its Relation to Adenylyl Cyclase.Proc. Natl. Acad. Sci.1970, 65, 745-752. 
47. Lefkowitz, R. J.; Roth, J.; Pastan, I. Radioreceptor Assay for Adrenocorticotropic Hormone: New Approach to Assay of Polypeptide Hormones in Plasma. Science 1970,170, 633-635.

48. Abuin, A.; Holt, K.H.; Platt, K.A.; Sands, A.T.; Zambrowicz, B.P. (2002). Full-speedmammalian genetics: in vivo target validation in the drug discovery process.Trends Biotechnol., Vol. 20, no. 1, pp. 36-42

49. Black, J.W. (2000) Introduction: Bioassays past uses and future potentials, In: The Pharmacology of Functional, Biochemical, andRecombinant Receptor Systems, Kenakin, T. and Angus, J.A., pp. 1-11, Springer-Verlag, ISBN 3-540-66124-7, Berlin.

50. Congreve, M.; Murray, C.W.; Blundell T.L. (2005). Keynote review: Structural Biology and Drug Discovery. Drug Discovery Today, Vol. 10, no. 13, pp. 895-907.

51. Klebe, G. (1995). Toward a more efficient handling of conformational flexibility in computerassisted modeling of drug molecules. Persp Drug Discov Design, Vol. 3, pp. 85-105.

52. Nielsen, K.J.; Adarns, D.; Thomas, L.; Bond, T.; Alewood, P.F.; Craik, D.J.; Lewis, R.J. (1999). Structure-activity relationships of omega-conotoxins MVIIA, MVIIC and 14 loopsplice hybrids at $\mathrm{N}$ and P/Q-type calcium channels. J. Mol. Biol., vol 289, no. 5, pp.1405-1421.

53.Richard, F.; Clark, M.A.; Cubeddu, L.X. (Eds.). (2009). Lippincott's Illustrated Reviews:Pharmacology, Lippincott Williams \& Wilkins, ISBN 978-0-7817-7155-9, pp. 348-358,

54. Baltimore.Scheraga, H. A. In Lipkowitz, K. B.; Boyd, D. B. Eds. (1992) Revisions in Computational Chemistry, VCH, New York, pp. 73-142.

55. Singh, R.; Nagori, B.P.; Soni, B.; Singh, J.V.(2011). A Review: Clinical Trial and DataManagement. Pharmacophore, Vol. 2, no. 3, pp. 200-209.

56.Wold, S.; Ruhe, A.; Wold, H.; Dunn, W.J. (1984). The collinearity problem in linearregression. The partial least squares approach to generalized inverse. SIAM J. Sci.Stat. Comput., Vol. 5, pp. 735-743.

57. Xue, L.; Bajorath, J. (2000). Molecular descriptors in chemoinformatics, computationalcombinatorial chemistry, and virtual screening. Comb. Chem. High ThroughputScreen., Vol. 3, pp.363-372.
58. Broach JR, Thorner J. High throughput screening for drug discovery.Nature 1996; 7:14-6.

59. Burger A. Medicinal Chemistry. New York: Wiley; 1970.

60. Charifson PS. Practical Application of Computer-Aided Drug Design.New York: Marcel Dekker; 1997.

61. Cohen NC, Blaney JM, Humblet C, Gund P, Barry DC. Molecular modelingsoftware and models for medicinal chemistry. J MedChem 1990; 33:88394.

62. Farber GK. New approaches to rational drug design. PharmacolTher1999; 84:327-32.

63. King PM, Reynolds CA, Worth GA, Richards WG. Free energy calculationsof pharmaceutically important properties. Mol Simul 1990; 5:265-72.

64. Gane PJ, Dean PRational programs usedM. Recent advances in structurebased rational drug design. CurrOpin Struct Biol 2000; 10:401-4.

65. Ganellin CR. Past approaches to discovering new drugs. In: WermuthCG, editor. Medicinal Chemistry for the 21st Century. Oxford: Blackwell;1992. p. 312.

66. Ghose AK, Viswanadhan VN, Wendoloski JJ. A knowledge-basedapproach in designing combinatorial or medicinal chemistry librariesfor drug discovery: 1,A qualitative and quantitative characterizationof known drug databases. J Comb Chem 1999; 1:55-68.

67. Good AC, So SS, Richards WG. Structureactivity relationships frommolecular similarity matrices. J Med Chem 1993; 36:433-42.

68. Grabley S, Thiericke R. Drug discovery from nature. Berlin, Germany:Springer; 1999.

69. Lipinski CA, Lombardo F, Dominy BW, Feeney PJ. Experimental andcomputational approaches to estimate solubility and permeabilityin drug discovery and development settings. Adv Drug Deliv Rev2001; 46:3-26.

70. Luscombe NM, Greenbaum D, Gerstein M. What is bioinformatics?A proposed definition and overview of the field. Methods Inf Med2001; 40:346-58.

71. Manly CJ, Louise-May S, Hammer JD. The impact of informatics andcomputational chemistry on synthesis and screening. Drug Discov Today 2000; 6:1101-10. 
72. Meyer AY, Richards WG. Similarity of molecular shape. J Comput AidedMol Design 1991; 5:427-36.

73. Meyer EF, Swanson SM, Williams JA. Molecular modelling and drugdesign. PharmacolTher2000; 85:113-21.

74. Mulholland AJ, Grant GH, Richards WG. Computer modelling of enzymecatalysed reaction mechanisms. Protein Eng1993; 6:133-9.

75. Ohlstein EH, Ruffolo RR Jr, Elliott JD. Drug discovery in the nextmillennium. Annu Rev PharmacolToxicol2000; 40:177-91.

76. oms F. Molecular modeling and computer aided drug design.Examples of their applications in medicinal chemistry. Curr Med Chem2000; 7:14158.

77. Perun TJ, Propst CL. Computer-aided drug design. New York: MarcelDekker; 1989.

78. Podlogar BL, Muegge I, Brice LJ. Computational methods to estimatedrug development parameters.CurrOpin Drug DiscovDevel2001; 4:129.

79. Ramstrom O, Lehn JM. Drug discovery by dynamic combinatoriallibraries. Nat Rev Drug Discov2002; 1:26-36.

80. Richards WG. Computer-aided drug design. Pure Appl Chem1994; 66:1589-96.

81. Rudin M, Weissleder R. Molecular imaging in drug discovery anddevelopment. Nat Rev Drug Discov2003; 2:123-31.

82. Sneader W. Drug discovery: The evolution of modern medicines.Chichester: Wiley; 1985.

83. Terstappen GC, Reggiani A. In silico research in drug discovery. TrendsPharmacol Sci 2000; 22:23-6.

84. Abell AN, Rivera-Perez JA, Cuevas BD, Uhlik MT, Sather S,Johnson NL et al. (2005). Ablation of MEKK4 kinase activity causesneurulation and skeletal patterning defects in the mouse embryo. Mol Cell Biol 25: 8948-8959.

85. Bertram L, Tanzi RE (2008). Thirty years of Alzheimer's diseasegenetics: the implications of systematic meta-analyses. Nat RevNeurosci 9: 768778.

86. Boppana K, Dubey PK, Jagarlapudi SARP, Vadivelan S, Rambabu G(2009). Knowledge based identification of MAO-B selectiveinhibitors using pharmacophore and structure based virtual screening models. Eur J Med Chem 44: 3584-3590.
87. Castanotto D, Rossi JJ (2009). The promises and pitfalls ofRNA-interference-based therapeutics. Nature 457: 426-433.

88. Chessell IP, Hatcher JP, Bountra C, Michel AD, Hughes JP, Green Pet al. (2005). Disruption of the P2X7 purinoceptor gene abolisheschronic inflammatory and neuropathic pain. Pain 114: 386396.

89. Cox JJ, Reimann F, Nicholas AK (2006). An SCN9A channelopathycauses congenital inability to experience pain. Nature 444: 894-898.

90. Dunne A, Jowett M, Rees S (2009). Use of primary cells in highthroughput screens. Meth Mol Biol 565: 239-257. 91. Fox S, Farr-Jones S, Sopchak L, Boggs A, Nicely AW, Khoury R et al.(2006). High-throughput screening; Update on practices and success. J Biol Screen 11: 864-869.

92. Frearson JA, Collie IT (2009). HTS and hit finding in academia -from chemical genomics to drug discovery. Drug Discov Today 14:1150-1158.

93. Henning SW, Beste G (2002). Loss-of-function strategies in drugtarget validation. Curr Drug Discov May: 17-21.

94. Honore P, Kage K, Mikusa J, Watt AT, Johnston JF, Wyatt JR et al.(2002). Analgesic profile of intrathecal P2X3 antisenseoligonucleotide treatment in chronic inflammatory andneuropathic pain states. Pain 99: 11-19.

95. Kurosawa G, Akahori Y, Morita M, Sumitomo M, Sato N,Muramatsu C et al. (2008). Comprehensive screening for antigensoverexpressed on carcinomas via isolation of human mAbs thatmay be therapeutic. Proc Natl Acad Sci U S A 105: $7287-$ 7292.

96. Law R, Barker O, Barker JJ, Hesterkamp T, Godemann R,Andersen O et al. (2009). The multiple roles of computationalchemistry in fragment-based drug design. J Comput Aided Mol Des 23: 459-473.

97. Lipinski CA, Lombardo F, Dominy BW, Feeney PJ (2001).Experimental and computational approaches to estimate solubilityand permeability in drug discovery and developmentsettings. AdvDrug Deliv Rev 46: 3-26.

98. McInnes C (2007). Virtual screening strategies in drug discovery.CurrOpin Chem Biol 11: 494-502. 
99. Michelini E, Cevenini L, Mezzanotte L, Coppa A, Roda A (2010).

100. Cell Based Assays: fuelling drug discovery. Anal Biochem 397: 1-10.

101. Moore K, Rees S (2001). Cell-based versus isolated target screening:how lucky do you feel? J BiomolScr 6: 69-74.

102. Peet NP (2003). What constitutes target validation? Targets 2:125-127.

103. Stables J, Mattheakis LC, Chang TR, Rees S (2000). Recombinantaequorin as a reporter of changes in intracellular calciumconcentration in mammalian n cells. Meth Enzymol 327: 456-471.

104. Ugolini G, Marinelli S, Covaceuszach S, Cattaneo A, Pavone F(2007). The function neutralizing anti-TrkA antibody MNAC13 reduces inflammatory and neuropathic pain. Proc NatlAcad Sci U SA 104: 2985-2990.

105. Whitehead KA, Langer R, Anderson DG (2009). Knocking downbarriers: advances in siRNA delivery. Nature Rev Drug Discov 8:129-138.

106. Yang Y, Wang Y, Li S (2004). Mutations in SCN9A, encoding asodium channel alpha subunit, in patients with primaryerythermalgia. J Med Genet 41: 171-174.

107. Yang Y, Adelstein SJ, Kassis AI (2009). Target discovery from datamining approaches. Drug Discov Today 14: 147-154.

108. Zanders ED, Bailey DS, Dean PM (2002). Probes for chemicalgenomics by design. Drug Discov Today 7: 711-718.

109. Zhang JH, Chung DY, Oldenberg KR (1999). A simple statisticalparameter for use in evaluation and validation of high throughputscreening assays. J BiomolScr 4: 67-73.

110. Aller, S.G., Yu, J., Ward, A., Weng, Y., Chittaboina, S., Zhuo, R., Harrell, P.M., Trinh, Y.T., Zhang, Q., Urbatsch, I.L., Chang, G., 2009. Structure of P-glycoprotein reveals amolecular basis for polyspecific drug binding. Science 323, 1718-1722.

111. Bazer, F.W., Spencer, T.E., Johnson, G.A., 2009. Interferons and uterine receptivity.Semin. Reprod. Med. 27, 90-102.

112. Cowan-Jacob, S.W., Fendrich, G., Floersheimer, A., Furet, P., Liebetanz, J., Rummel,
G.,Rheinberger, P., Centeleghe, M., Fabbro, D., Manley,P.W., 2007. Structural biology contributions to the discovery of drugs to treat chronic myelogenous leukaemia.Acta Crystallogr. Sect. D 63, 80-93.

113. Dahlquist, K.D., Salomonis, N., Vranizan, K., Lawlor, S.C., Conklin, B.R., 2002. GenMAPP, a new tool for viewing and analyzing microarray data on biological pathways. Nat.Genet. 31, 19-20.

114. Dennis Jr., G., Sherman, B.T., Hosack, D.A., Yang, J., Gao, W., Lane, H.C., Lempicki, R.A., 2003. DAVID, Database for Annotation, Visualization, and Integrated Discovery. 115. Genome Biol. 4, 3.Desco^ teaux, C., Provencher-Mandeville, J., Mathieu, I., Perron, V., Mandal, $\quad$ S.K., Asselina, E., Be' rube', G., 2003. Synthesis of 17estradiol platinum(II) complexes: biological evaluation on breast cancer cell lines.

116. Bioorg. Med. Chem. Lett. 13, 3927-3931.

117. Druker, B.J., Lydon, N.B., 2000. Lessons learned from the development of an Abl tyrosine kinase inhibitor for chronic myelogenous leukemia. J. Clin. Invest. 105, 3-7.

118. Eisen, M.B., Spellman, P.T., Brown, P.O., Botstein, D., 1998. Cluster analysis and display of genome-wide expression patterns. Proc. Natl. Acad. Sci. U. S. A. $95,14863-14868$.

119. Frenzel, A., Grespi, F., Chmelewskij, W., Villunger, A., 1998. BCl2 family proteins in carcinogenesis and the treatment of cancer. Apoptosis 14, 584-596.

120. Fukui, K., Yonezawa, T., Nagata, C., Shingu, H., 1954. Molecular orbital theory of orientation in aromatic, heteroaromatic, and other conjugated molecules. J. Chem. Phys. 22, 1433-1442.

121. Fuller, J.C., Burgoyne, N.J., Jackson, R.M., 2009. Predicting druggable binding sites at the protein-protein interface. Drug Discov. Today 14, 155-161.

122. Gagnon, V., St-Germain, M., Desco^teaux, C., Provencher-Mandeville, J., Parent, S., Mandal, S.K., Asselin, E., Be'rube, G., 2004. 